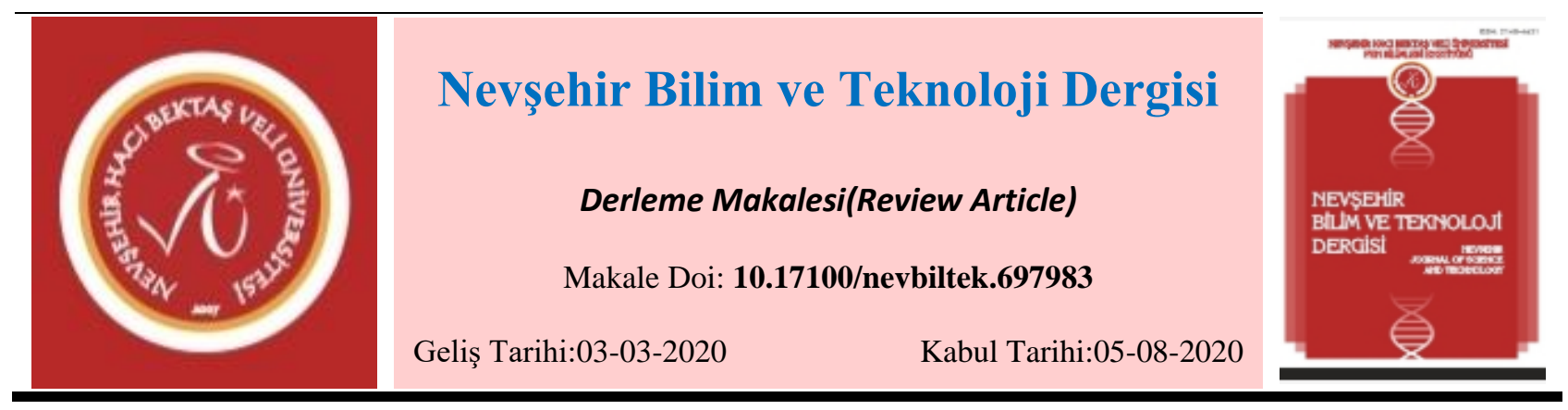

\title{
Gebelikte Kullanılan Kısa Mesaj Hizmeti Temelli Uygulamalar
}

\author{
Pelin CALPBİNiCi ${ }^{1}$, Aynur KIZILIRMAK ${ }^{2}$ \\ ${ }^{1}$ Nevşehir Hacı Bektaş Veli Üniversitesi, Sağlık Bilimleri Fakültesi, Hemşirelik Bölümü, Nevşehir \\ ORCID ID: 0000-0001-8242-2773 \\ ${ }^{2}$ Nevşehir Hacı Bektaş Veli Üniversitesi, Sağlık Bilimleri Fakültesi, Hemşirelik Bölümü, Nevşehir \\ ORCID ID: 0000-0002-5032-7234
}

$\ddot{\mathbf{O} z}$

Mobil Sağlık (mSağlı) uygulamaları arasında en yaygın olarak kullanılan teknoloji Kısa Mesaj Hizmeti (SMS)'dir. SMS yüksek kaliteli, düşük maliyetli, esnek ve hasta memnuniyeti yüksek sağlık hizmetinin sunulmasını olanak sağlamaktadır. Bu özelliğinden dolayı anne sağlığının korunması ve geliştirilmesinde bir firsat olarak görülmektedir. Bu makalede gebelikte kullanılan kısa mesaj hizmeti (SMS) temelli uygulama örneklerine yer verilmiş ve SMS temelli uygulamalarının gebelikte bilgi, tutum ve davranışa etkisine dair kanıtlar özetlenmiştir.

Anahtar Kelimeler: Mobil Sağlık, Gebelik, mSağlık, SMS, Metin Mesajı

Abstract

Text Message Based Interventions Used In Pregnancy

The most widely used technology among Mobile Health (mHealth) interventions is the text message. Text message enables the provision of high quality, low cost, flexible and patient satisfaction high health service. Due to this feature, it is seen as an opportunity to protect and improve maternal health. This article includes examples of text message based interventions used in pregnancy and the evidence of the effect of text message based interventions on knowledge, attitude and behavior in pregnancy.

Keywords: Mobile Health, Pregnancy, mHealth, SMS, Text Message

\section{Giriş}

Mobil teknolojiler günlük yaşamın ayrılmaz bir parçası haline gelmiştir. Statista 2019 verilerine göre dünyada 8.3 milyar mobil ağ aboneliği bulunmaktadır ve bu sayı 2022'de 9 milyarın üzerine çıkması beklenmektedir [1]. Mobil ağ aboneliği gelişmekte olan ülkelerarasında da hızla yayılmaktadır. Birçok düşük ve orta gelirli ülkelerde mobil ağ penetrasyonu yol, elektrik gibi altyapı sistemlerini aşmış ve sabit internet dağıtımını gölgede bırakmış durumdadır [2]. Mobil teknolojinin yaygın olarak kullanılması ve teknolojideki ilerlemeler yeni bir kavram olan Mobil Sağlı̆̆ın (mSağlık) ortaya çıkmasını sağlamıştır [3 ve 4].

Sağlığın standartlaştırılmış bir tanımı bulunmamaktadır. Dünya Sağlık Örgütü (DSÖ) mSağlı̆̆ı cep telefonları, hasta takip cihazları, kişisel dijital yardımcılar (PDA'lar) ve diğer kablosuz cihazlar gibi mobil cihazlar tarafından desteklenen tıbbi ve halk sağlığı uygulamaları olarak tanımlamıştır [2]. Birleşmiş Milletler "mSağlı̆̆ı Geliştirme" raporunda mSağlık; sağlık hizmetleri ve bilgi edinmek için PDA'lar ve cep telefonları gibi mobil iletişim araçlarının kullanılması olarak belirtilmiştir [3]. mSağlık, elektronik sağlığın (eSağlık) önemli bir bileşeni olarak ortaya çıkmıştır [3 ve 5]. eSağlık, sağlık hizmetlerinin sunumunu destekleyen ve çevrimiçi sağlık hizmetleri sunan bir teknoloji olarak kabul edilebilirken, mSağlık temel olarak sağlık hizmetlerine erişim sağlayan teknoloji olarak nitelendirilmektedir [5]. Bu teknolojiler; kısa mesaj hizmeti, akıllı telefon sağlık uygulamaları, giyilebilir ve kablosuz cihazları içerir [5 ve 6]. 
Sağlık uygulamaları arasında en yaygın olarak kullanılan uygulama Kısa Mesaj Hizmeti (SMS)'dir [7]. SMS, uzun yıllardır var olan bir teknolojidir ve çoğu cep telefonunun temel özelliğidir [8]. SMS'ler sağlık davranışlarını hatırlatmak, planlanan randevuları ve ilaç alımını hatırlatmak, klinik test sonuçlarını bildirmek, sağlık durumu bildirmek, olumlu sağlık davranışlarını teşvik etmek, bilgi ve kaynaklara erişim hakkında bilgilendirmek amacıyla kullanılmaktadır [9]. SMS'in sunduğu bu imkanlar yüksek kaliteli, düşük maliyetli, esnek ve hasta memnuniyeti yüksek sağlık hizmetinin sunulmasını sağlar [10]. Özellikle kısıtlı kaynakları ve sınırlı eğitimli personeli olan, ulaşılması zor nüfuslara sağlık hizmetinin ve sağlıkla ilgili bilgilerin ulaştırılması için önemli bir çözüm olarak görülmektedir [3 ve 11]. Bu özelliklerinden dolayı DSÖ tarafından anne sağlığının iyileştirmenin bir aracı olarak kullanımı teşvik edilmektedir [2]. SMS uygulamaları gebelikte sağlığın korunması ve geliştirilmesinde, gebenin kendi sağlığını takip etmesinde kullanılmaktadır. Bu makalede gebelikte kullanılan SMS uygulama örnekleri verilmiş ve SMS uygulamalarının gebelikte bilgi, tutum ve davranışa etkisine dair kanıtlar özetlenmiştir.

\section{Kısa Mesaj Hizmeti Temelli Uygulama Örnekleri}

SMS uygulamaları gebelikte sigarayı bırakmada, fiziksel aktiviteye ve aşılamaya teşvikte, sağlıklı beslenmede, gebelikteki diyabetin yönetiminde, doğum öncesi bakıma katılımı artırma gibi alanlarda kullanılmaktadır.

\subsection{Sigarayı Burakma}

Gebelikte sigara kullanımı fetüste; perinatal mortalite, düşük doğum ağırlığı, erken doğum, intrauterin gelişim geriliği ve doğum kusuru, annede ise ektopik gebelik, plasenta previa riskini artırmaktadır [12]. Bu nedenle, gebelikte sigaranın bırakılması hem anne hem de bebek sağlığı için büyük önem taşımaktadır. Kendi kendine yardım (self-help) yöntemi sigarayı bıraktırma yöntemlerinden biri olarak kabul edilmektir. Kendi kendine yardım genellikle yazilı materyaller biçimindedir, ancak video veya ses kaydı gibi media formlarını da içermektedir [13]. Günümüzde giderek yaygınlaşan kendi kendine yardım yöntemleri arasında SMS uygulamaları da yer almaktadır. Doğum öncesi bakımda sigarayı bıraktırmada SMS etkili bir yöntem olarak görülmektedir [14].

Naughton ve ark., (2012) MiQuit adlı gebelikte kullanılmak üzere kişiye özel sigara bırakmaya yönelik SMS programı geliştirmişlerdir. Randomize kontrollü yapılan bu çalışmada, müdahale grubuna 11 hafta boyunca kısa mesaj programı (MiQuit) uygulanmış ve uyarlanmış kendi kendine yardım broşürü verilmiş̧ir. Kontrol grubuna ise sadece uyarlanmamış kendi kendine yardım broşürü verilmiştir. Çalışma sonucunda, müdahale grubunda yer alan gebelerin öz yeterliliklerinin arttığı ve gebelerin 24 saat içerisinde sigara bırakma girişiminde bulunma olasılıklarının arttı̆̆ bulunmuştur [14]. Sloan ve ark. (2017) randomize kontrollü çalışmanın bir parçası olarak gebelik sırasında MiQuit programını kullanan 15 kadın ile yarı yapılandırılmış görüşmeler yapmıştır. Araştırma sonucunda SMS'lerin sigarayı bırakma konusunda kadınlarda motivasyonu artırdığı bulunmuştur [15].

Yakın zamanda yapılan, randomize kontrollü bir çalışmada ise SMS tabanlı bir programın gebelerin \%10'unun sigarayı bırakmasına yardımcı olduğunu saptamıştır [16]. Buna karşın Heminger ve ark. (2016) gebelikte sigara bırakmada SMS programlarını etkinliğini değerlendirmek için çok az çalışma yapıldığını ve bu çalışmaların çoğunluğunun küçük örneklem büyüklüklerinde olan pilot çalışmalar olduğunu belirtmiştir [17].

\subsection{Grip Aşııs}

Grip, gebelerde ve yeni doğum yapmış kadınlarda gebe olmayan kadınlara oranla daha ağır seyreder. Gebelikte ağır seyreden grip erken doğum riskini de artırabilmektedir [18]. Gebelikte grip aşısının yapılmasına ilişkin çalışmalar bulunmaktadır [19]. Gebelikte grip aşısına yönelik gebeleri bilinçlendirmek ve harekete geçirmek için SMS temelli çalışmalarda literatürde yer almaktadır [18, 20-22]. Jordan ve ark. (2015) yaptığı çalışmada, SMS uygulamasının gebelikte aşılama oranını arttırdığı bulunmuştur. Ayrıca aşı maliyetinin düşük olduğuna yönelik özel bir mesaj, maliyet nedeniyle aşı olmayı düşünmeyen kadınlar arasında da aşılanma oranını yükselttiği bildirilmiştir [19]. Diğer taraftan 
Nevşehir Bilim ve Teknoloji Dergisi (2020), 9(2) 92-98

gebelikte grip aşısının önemine yönelik haftalık metin mesajları, gebeler arasında aşılama oranlarının artırılmasında etkili olmadı̆̆ını gösteren çalışmalarda bulunmaktadır [21 ve 22].

\subsection{Doğum Öncesi Bakım}

Doğum öncesi bakım, sağlığın teşviki ve geliştirilmesi, tarama, teşhis ve hastalıkların önlenmesi için önemlidir [23]. Gebelerin sağlıklı davranışlar benimsemeleri ve sürdürmeleri için Evans ve ark. Text4baby adlı bir SMS programı geliştirmişlerdir. Randomize kontrollü yaptıkları çalışmada müdahale grubunda bulunan kadınlara gebelikte beslenme, ruh sağlığı, mevsimsel gribin önlenmesi ve tedavisi, ağız sağlı̆̆ı, sigara kullanımı, emzirme, aşı programları ve yenidoğanda güvenli uyku konularında haftada üç kez olacak şekilde SMS göndermişlerdir [24 ve 25]. Çalışma sonucunda; müdahale grubundaki gebelerde“anne olmaya hazırım” tutum ifadesinin başlangıca göre arttığını, son 30 gün içinde sigara içtiğini bildiren kadınların oranının azaldığını, kadınların alkol tüketimine yönelik tutumlarında ise olumlu bir gelişme gösterdiği bulunmuştur. Text4baby programının kullanıldığı başka bir randomize kontrollü çalışmada ise metin mesajlarının kadınlarda gebelikte vitamin alımını artırdığı, doğum öncesi bakımın önemine ve alkol tüketiminin zararlarına yönelik inancı artırdığg saptanmıştır [26].

Oliveira-Ciabat ve ark., gebelik, doğum, doğum öncesi ve doğum sonrası bakım hakkında bilgi veren ve gebelerin spesifik sorularına cevap verebilen çift yönlü kısa mesaj hizmeti uygulaması olan PRENACEL programını değerlendirmek amacı ile randomize kontrollü bir çalışma yürütmüşlerdir. Çalışma sonucunda; SMS uygulamasının gebelikte 75 gr oral glukoz tolerans testini, sifiliz, HIV tarama testlerini yaptırmayı artırdığı, folik asit alma oranını ve doğum öncesi bakım almayı artırdığı bulunmuştur [27]. Lund ve ark. (2014) Zanzibar'da yaptığı randomize kontrollü çalışmada da SMS uygulamasının gebelikte önerilen dört kez doğum öncesi bakım ziyaretini alma oranını önemli ölçüde artırdı̆̆ saptanmıştır [28].

Song ve ark., düşük gelirli 23 gebe kadında çift yönlü otomatik kısa mesaj hizmetinin işlevselliğini (ör. sistemin kullanım kolaylığı, kullanılabilirlik, kapsam ve doğruluk) ve sistemi kullanmanın gerçek hayattaki sonuçlarını (ör. gebelikle ilgili bilgi edinme, sağlık profesyonelleri ile iletişimini kolaylaştırma ve stresi azaltma) değerlendirmek amacıyla ön test-son test odak grup çalışması yürütmüşlerdir. Çalışmada, katılımcılardan bir ay boyunca kısa mesaj hizmetini kullanarak gebeliğe ilişkin sorular sormaları istenmiştir. Hangi soruları sordukları tamamen kendi inisiyatiflerine bırakılmıştır. Katılımcılar 48 saat içinde soru göndermemişler ise sistemi kullanmaya teşvik eden hatırlatıcı mesajlar gönderilmiştir. Çalışma sonunda katılımcılar veri tabanına toplamda 161 farklı başlıkta 291 soru gönderilirken, en çok sorulan sorular ise yaygın karın ağrısı/kramp, kasılmalar/doğum, bebek hareketi konuları ile ilişkisi sorular olmuştur. Song ve ark. iki yönlü otomatik kısa mesaj sisteminin hedef kitleye sağlık bilgisi vererek ve hastasağlık profesyonelleri arasında sağlık iletişimini destekleyerek iletişimi kolaylaştırdığını ve gebelerde psikolojik iyilik halini artırdığını bildirmişlerdir. Ayrıca sistemin kullanımı, gebeleri soru üretmeye ve gebelikle ilgili bilgi aramaya teşvik ettiği de belirtilmiştir [29].

\subsection{Maternal Obezite Yönetimi}

Maternal obezite, anne, fetüs ve yenidoğan sağlığı yönden istenmeyen sonuçları artmaktadır. Gebelik öncesi ve gebelik döneminde kadınların diyetlerinin düzenlenmesi istenmeyen sonuçların ortaya çıkmasını azaltmaktadır [30]. Bu kapsamda Soltani ark. maternal obezite yönetimi için MOMTech SMS programını geliştirmiştir. MOMTech, kilo yönetimini desteklemek için kanıta dayalı bilgilerin yer aldı̆̆ı kısa mesaj uygulamasıdır. Çalışmada, müdahale grubunda bulunan kadınlara sağlıklı beslenmeye ve fiziksel aktiviteye teşvik eden günlük mesajlar gönderilirken, kontrol grubunda yer alan gebelere herhangi bir müdahalede bulunulmamıştır. Çalışma sonunda müdahale grubundaki kadınların gebelikte ortalama kilo alımı $(5.6 \mathrm{~kg})$, kontrol grubundan $(9.7 \mathrm{~kg})$ daha düşük bulunmuştur [31].

\subsection{Gestasyonel Diyabet Yönetimi}


Nevşehir Bilim ve Teknoloji Dergisi (2020), 9(2) 92-98

Gestasyonel diyabet (GDM) ilk kez gebelikte teşhis edilen, maternal (preeklampsi, enfeksiyon, polihidroamnioz vb.) ve neonatal (makrozomi, hiperbilirubinemi, doğumsal travmalar, respiratuar distres sendromu, hipoglisemi vb.) morbidite ve mortaliteyi artıran bir gebelik komplikasyonudur [32]. Diyabetin neden olduğu komplikasyonların önlenmesi için hastanın doğru takibi edilmesi ve metabolik kontrolün sağlanması önemlidir [33]. Perez-Ferre ve ark. bu takiplerin telefon tabanlı uygulamalar aracılığıyla yapılabileceğini belirtmiştir. İspanya'da yapılan yarı randomize bir çalışmada, gestasyonel diyabet tedavisi alan kadınlar müdahale ve kontrol grubuna atanarak randomize edilmişlerdir. Müdahale grubuna atanan kadınlara, cep telefonu ve glikometre verilmiş ve kontrol grubunda yer alan kadınlara müdahalede bulunulmamıştır. Kadınlara verilen telefonda, kan glikoz değerlerinin SMS aracılı̆̆ıla veri tabanına iletilmesine izin veren bir ön kurulum uygulaması içermektedir. Bu uygulama aynı zamanda ölçüm cihazında depolanan glikoz değerlerinin cep telefonuna kızılötesi ile iletilmesine izin veren bir ara yüze de sahiptir. Kadının ölçtüğü kan glikoz değerleri web uygulamasına kaydedilerek, sağlık personeli tarafından kadına SMS aracılığı ile insülin dozunda ve beslenme konusunda danışmanlık verilmiştir. Çalışma sonucunda müdahale ve kontrol grubu arasında diyabet kontrollerinde anlamlı bir fark bulunmazken, insüline bağımlı olan kadınlarda poliklinik ziyaretlerinde belirgin bir azalma görülmüştür [33].

\subsection{HIV Pozitif Gebelerde Gebelik Yönetimi}

HIV, Sahra-altı Afrika'da sağlık sistemleri üzerinde önemli bir yük olmaya devam etmektedir. 2013 y1lında Güney Afrika'da HIV ile ilişkili hastalık anne ölümlerinin yaklaşık \%42'sinden sorumlu tutulmaktadır. Gebelerin anne sağlığı hizmetlerinden faydalanmalarının sağlanması, yüksek riskli obstetrik vakaların belirlenmesi, HIV ile enfekte olmuş kadınların belirlenmesi, anti-retroviral tedavinin başlatılması ve etkinliğinin izlenmesi için yenilikçi ve hasta merkezli çözümlere ihtiyaç duyulmuştur [34]. Coleman ve ark. Güney Afrika'da gebe kadınların doğum öncesi bakıma devam etmelerini artırmak, HIV pozitif kadınlar ve bebekler için doğum sonuçlarını iyileştirmek, doğum sonrası bebek HIV testi uygulamasını artırmak için SMS uygulamasını kullanmışlardır. Çalışmada müdahale grubunda yer alan 235 HIV ile enfekte gebeye doğuma kadar, haftada iki kez, gebelik/bebek sağlığ 1 ve HIV ile ilgili bilgileri kapsayan SMS’ler gönderilmiştir. Kontrol grubunda yer alan 586 HIV enfekte gebeye ise müdahalede bulunulmamış, standart bakım verilmiştir. Çalışma sonucu müdahale grubunda yer alan gebelerin daha fazla doğum öncesi bakıma katıldığı, doğumdan sonraki altı hafta içinde yenidoğan polimeraz zincir reaksiyonu testine daha fazla yaptırdığı ve düşük doğum ağırlıklı bebek doğurma riski azaldığı bulunmuştur [34].

\subsection{Fiziksel Aktivite Yönetimi}

Gebelikte fiziksel aktivite, hem anne hem de fetüs sağlık için önemli yararları vardır. Anne için fiziksel aktivite, gestasyonel diyabetin önlenmesi ve kontrolü, aşırı kilo alımı ve bel ağrısında azalma, preklemsi ve preterm doğum riskinde azalma, azalmış anksiyete ve gelişmiş sağlık algısı ile ilişkiliyken, fetüs için ise normal doğum ağırlı̆gı ile ilişkilidir [35 ve 36]. Amerikan Jinekoloji ve Obstetrik Derneği (ACOG), gebelik sırasında ve sonrasında kadınlar için haftada en az 150 dakika orta yoğunluklu aerobik aktivite yapılmasını (tempolu yürüyüşe eşdeğer) önermektedir [37]. Aşırı kilolu veya obez olanlarda dahil olmak üzere gebelerin \%80'ninden fazlası ve gestasyonel diabetes mellituslu kadınların \%60'ından fazlası önerildiği gibi fiziksel aktivite yapmamaktadır[36]. Gebelerin doğum öncesi dönemde yeterli fiziksel aktivite seviyelerine ulaşmaları ve sürdürmeleri konusunda çeşitli girişimler bulunmaktadır. Bu girişimlerden biride SMS uygulamalardır. Huberty ve ark. gebelerde fiziksel aktiviteyi iyileştirmek için SMS uygulamasının etkinliğini ve SMS'in uygulama zamanını ve sıklığını değerlendirmek amacıyla randomize kontrollü bir çalışma yürütmüştür. Çalışmada, bir gruba sadece Text4baby uygulaması (Text4baby içeriğinde fiziksel aktiviteyi teşvik eden sadece dört mesaj içer), bir gruba Text4baby uygulaması ve haftada iki kez öğlen fiziksel aktivite mesajı, bir gruba Text4baby uygulaması ve haftada altı kez öğlen fiziksel aktivite mesajı, bir gruba ise Text4baby uygulaması ile haftada altı kez kendi seçtikleri saatte altı fiziksel aktivite mesajı uygulanmıştır. Çalışma sonucunda, SMS sıklığından ve zamanından bağımsız 
Nevşehir Bilim ve Teknoloji Dergisi (2020), 9(2) 92-98

olarak gebelerde fiziksel aktivitede artış olmamıştır. Haftada altı fiziksel aktivite mesajı alanların fiziksel aktivitesinde daha fazla azalma olmuştur. Gebelerde fiziksel aktivite davranışını iyileştirmek için SMS kullanımı hala başlangıç aşamasında olduğu ve bu alanda daha fazla çalışmalara ihtiyaç duyulmaktadır [35].

3. Sonuç

Bu makalede gebelikte kullanılan SMS temelli uygulama örneklerinin bir kısmına yer verilmiştir. SMS uygulamaları gebelikte sigarayı bırakmada, fiziksel aktiviteye ve aşılamaya teşvikte, beslenmede, gestasyonel diyabetin yönetiminde, doğum öncesi bakıma katılımı artırmada kullanılmaktadır. SMS'in gebelikte kullanımı umut vadeden interaktif bir yaklaşımdır. Özellikle kısıtlı kaynakları ve sınırlı eğitimli personeli olan, ulaşılması zor nüfuslara sağlık hizmetinin ve sağlıkla ilgili bilgilerin ulaştırılması için önemli bir gelişmedir. Bu alanda çalışan başta hemşireler olmak üzere sağlık çalışanlarının annenin ve bebeğin sağlığını korumak, bakım kalitesini artırmak, maliyet etkili bakım sunmak ve zamandan tasarruf sağlamak için teknolojik gelişmeleri takip etmeleri gerekmektedir.

\section{Kaynaklar}

[1] Statista. "Number of mobile (cellular) subscriptions worldwide from 1993 to 2019" Erişim: https://www.statista.com/statistics/262950/global-mobile-subscriptions-since-1993/ Erişim Tarihi: 19.02.2020.

[2] World Health Organization (WHO). "mHealth: new horizons for health through mobile Technologies" 2011 Erişim: https://www.who.int/goe/publications/goe mhealth_web.pdf? Erişim Tarihi: 19.02.2020.

[3] Consulting V. W. "mHealth for development: the opportunity of mobile technology for healthcare in the developing World" Washington Dc and Berkshire, UK: United Nations, 2009.

[4] Martínez-Pérez B., De La Torre-Díez I., López-Coronado M., "Mobile health applications for the most prevalent conditions by the World Health Organization: review and analysis" Journal of Medical Internet Research, 15(6), 120, 2013.

[5] Sadiku M.N., Shadare A.E., Musa S.M., “Mobile Health” International Journal of Engineering Research, 6(10), 450-452, 2017.

[6] Bhavnani S.P., Narula J., Sengupta P.P., "Mobile technology and the digitization of healthcare" European Heart Journal, 37(18), 1428-1438, 2016.

[7] Poorman E., Gazmararian J., Parker R.M., Yang B., Elon L., "Use of text messaging for maternal and infant health: a systematic review of the literatüre" Maternal and Child Health Journal, 19(5), 969-989, 2015.

[8] Chow C.K., Ariyarathna N., Islam S.M.S., Thiagalingam A., Redfern J., "mHealth in cardiovascular health care" Heart, Lung and Circulation, 25(8), 802-807, 2016.

[9] Balci A.S., Kadioglu H., "Text Messages Based Interventions for Pregnant Women's Health: Systematic Review" Clinical and Experimental Health Sciences, 9(1), 85-90, 2019.

[10] Güler Ö.G.E., "Mobil sağlık hizmetlerinde oyunlaştırma" Açı̈̌̈̆gretim Uygulamaları ve Araştırmaları Dergisi, 1(2), 82-101, 2015.

[11] Aranda-Jan C. B., Mohutsiwa-Dibe N., Loukanova S., "Systematic review on what works, what does not work and why of implementation of mobile health (mHealth) projects in Africa" BMC Public Health, 14(1), 188, 2014. 
Nevşehir Bilim ve Teknoloji Dergisi (2020), 9(2) 92-98

[12] Phillips J.K., Skelly J.M., King S.E., Bernstein I. M., Higgins S.T., "Associations of maternal obesity and smoking status with perinatal outcomes" The Journal of Maternal-Fetal \& Neonatal Medicine, 31(12), 16201626, 2018.

[13] Whittaker R., McRobbie H., Bullen C., Rodgers A., Gu Y., "Mobile phone-based interventions for smoking cessation" Cochrane Database of Systematic Reviews, (4), 2016.

[14] Naughton F., Prevost A. T., Gilbert H., Sutton S., "Randomized controlled trial evaluation of a tailored leaflet and SMS text message self-help intervention for pregnant smokers (MiQuit)" Nicotine \& Tobacco Research, 14(5), 569-577, 2012.

[15] Sloan M., Hopewell S., Coleman T., Cooper S., Naughton F., "Smoking cessation support by text message during pregnancy: a qualitative study of views and experiences of the MiQuit intervention" Nicotine \& Tobacco Research, 19(5), 572-577, 2017.

[16] Pollak K. I., Lyna P., Gao X., Noonan D., Berjarano Hernansex S., Subudhu, S., et al., "Efcacy of a texting program to promote cessation among pregnant smokers: A randomized control trial" Ncotine \& Tobacco Research, 1-8, 2019.

[17] Heminger C. L., Schindler-Ruwisch J. M., Abroms L. C., "Smoking cessation support for pregnant women: role of mobile technology" Substance Abuse and Rehabilitation, 7, 15, 2016.

[18] Jordan E.T., Bushar J.A., Kendrick J. S., Johnson P., Wang J., "Encouraging influenza vaccination among Text4baby pregnant women and mothers" American Journal of Preventive Medicine, 49(4), 563-572, 2015.

[19] Salam RA, Das JK, Dojo Soeandy C, Lassi ZS, Bhutta ZA., Impact of Haemophilus influenzae type B (Hib) and viral influenza vaccinations in pregnancy for improving maternal, neonatal and infant health outcomes. Cochrane Database of Systematic Reviews, 6, 2015.

[20] Kharbanda E. O., Vargas C. Y., Castaño P. M., Lara M., Andres R., Stockwell M. S., "Exploring pregnant women's views on influenza vaccination and educational text messages" Preventive Medicine, 52(1), 75-77, 2011.

[21] Moniz M.H., Hasley S., Meyn L.A., Beigi R.H., "Improving influenza vaccination rates in pregnancy through text messaging: a randomized controlled trial” Obstetrics \& Gynecology, 121(4), 734-740, 2013.

[22] Yudin M.H., Mistry N., De Souza L.R., Besel K., Patel V., Mejia S. B., et al., "Text messages for influenza vaccination among pregnant women: a randomized controlled trial" Vaccine, 35(5), 842-848, 2017.

[23] World Health Organization (WHO)., "WHO recommendations on antenatal care for a positive pregnancy experience” 2016 Erişim: https://apps.who.int/iris/bitstream/handle/10665/250796/9789241549912eng.pdf;jsessionid=E42813888FB8F743B0D5CDB4031DC2AF?sequence=1 Erişim Tarihi: 9.02.2020.

[24] Evans WD, Wallace JL, Snider J., "Pilot evaluation of the text4baby mobile health program" BMC Public Health, 12, 1031, 2012.

[25] Jordan E. T., Ray E.M., Johnson P., Evans W. D., "Text4Baby: using text messaging to improve maternal and newborn health" Nursing for Women's Health, 15(3), 206-212, 2011. 
Nevşehir Bilim ve Teknoloji Dergisi (2020), 9(2) 92-98

[26] Evans WD, Wallace Bihm J, Szekely D, Nielsen P, Murray E, Abroms L, Snider J., "Initial outcomes from a 4week follow-up study of the text4baby program in the military women's population: randomized controlled trial" Journal of Medical Internet Research,16(5), 131, 2014.

[27] Oliveira-Ciabati L., Vieira C. S., Franzon A. C. A., Alves D., Zaratini F. S., Braga G., et al., "PRENACEL-a mHealth messaging system to complement antenatal care: a cluster randomized trial" Reproductive Health, 14(1), 146, 2017.

[28] Lund S., Nielsen B. B., Hemed M., Boas I. M., Said A., Said K., et al., "Mobile phones improve antenatal care attendance in Zanzibar: a cluster randomized controlled trial” BMC Pregnancy and Childbirth, 14(1), $29,2014$.

[29] Song H., May A., Vaidhyanathan V., Cramer E.M., Owais R.W., McRoy S., “A two-way text-messaging system answering health questions for low-income pregnant women" Patient Education and Counseling, 92(2), 182$187,2013$.

[30] Daşıkan Z., Kavlak O., "Maternal Obezite: Gebelik komplikasyonları ve gebe kadının yönetimi. Türkiye Klinikleri” Journal of Nursing Sciences, 1(1), 39-46, 2009.

[31] Soltani H., Duxbury A., Arden M. A., Dearden A., Furness P. J., Garland C., "Maternal obesity management using mobile technology: a feasibility study to evaluate a text messaging based complex intervention during pregnancy” Journal of Obesity, 1-10, 2015.

[32] Metin S., “Gestasyonel Diyabette Güncel Tedavi Yaklaşımları” Başkent Üniversitesi Sağllk Bilimleri Fakültesi Dergisi, 2(1), 2017.

[33] Pérez-Ferre N., Galindo M., Fernández M. D., Velasco V., Runkle I., de la Cruz M. J., et al., “The outcomes of gestational diabetes mellitus after a telecare approach are not inferior to traditional outpatient clinic visits" International Journal of Endocrinology, 10,1-6, 2010.

[34] Coleman J., Bohlin K. C., Thorson A., Black V., Mechael P., Mangxaba J., Eriksen J., "Effectiveness of an SMSbased maternal mHealth intervention to improve clinical outcomes of HIV-positive pregnant women" AIDS Care, 29(7), 890-897, 2017.

[35] Huberty J. L., Buman M. P., Leiferman J. A., Bushar J., Hekler E. B., Adams M. A., "Dose and timing of text messages for increasing physical activity among pregnant women: a randomized controlled trial" Translational Behavioral Medicine, 7(2), 212-223, 2017.

[36] Harrison A. L., Taylor N. F., Shields N., Frawley H. C., “Attitudes, barriers and enablers to physical activity in pregnant women: a systematic review" Journal of Physiotherapy, 64(1), 24-32, 2018

[37] American College of Obstetricians and Gynecologists (ACOG). "Physical activity and exercise during pregnancy and the postpartum period" Committee Opinion, 126,135-142, 2015. 